\title{
Excitatory Synaptic Transmission in Neostriatal Neurons: Regulation by Cyclic AMP-Dependent Mechanisms
}

\author{
Christopher S. Colwell and Michael S. Levine \\ Mental Retardation Research Center, University of California-Los Angeles, Los Angeles, California 90024-1759
}

The purpose of the present study was to examine whether cAMP-dependent mechanisms regulated excitatory synaptic transmission in the neostriatum. A brain slice preparation was utilized for intracellular recordings of the excitatory postsynaptic potentials (EPSPs) evoked by electrical stimulation. Bath application of forskolin, an activator of adenylate cyclase, enhanced the EPSP amplitude and duration. This potentiation was dose dependent and did not occur with the inactive analog 1,9-dideoxyforskolin. Forskolin potentiation was unaltered by treatment with the GA$B A_{A}$ receptor antagonist bicuculline. Furthermore, two inhibitors of cAMP-dependent protein kinase (PKA), Rp-cAMPS and IP ${ }_{20}$-amide, attenuated forskolin's enhancement of the EPSP. In addition, the PKA activator Sp-cAMPS enhanced excitatory synaptic transmission. Interestingly, treatment with PKA inhibitors alone depressed while the phosphatase inhibitor okadaic acid enhanced the synaptic response. These results suggest a role for tonic kinase and phosphatase activity in regulating excitatory synaptic transmission in the neostriatum. Finally, forskolin was found to enhance the responses of neostriatal neurons to glutamate receptor agonists. This potentiation, which occurred in the presence of tetrodotoxin, provides at least part of the explanation for the CAMP/PKA-dependent regulation of the EPSP. Overall, these results suggest a role for the adenylate cyclase cascade in the regulation of excitatory synaptic transmission in the neostriatum.

[Key words: CAMP, forskolin, glutamate, neostriatum, NMDA, okadaic acid, CAMP-dependent protein kinase (PKA), phosphatase]

The mammalian neostriatum plays a critical role in motor and cognitive functions. A major source of excitatory innervation of the neostriatum is the projection from the cerebral cortex which utilizes the excitatory amino acid glutamate as a transmitter (McGeer et al., 1977; Fonnum et al., 1981). There are two general forms of glutamate receptors (GluRs): (1) ionotropic GluRs which are ligand-gated cation channels; and (2) metabotropic GluRs which are coupled to various signal transduction processes through GTP binding proteins (Monaghan et al., 1989; Hollmann and Heinemann, 1994). The ionotropic GluRs can be further classified into three broad subtypes as $N$-methyl-D-as-

\footnotetext{
Received May 23, 1994; revised Aug. 4, 1994; accepted Aug. 18, 1994.

We thank Dr. N. Wayne for comments on an early draft of this manuscript This work was supported by HD05958 to M.S.L. and MN10735 to C.S.C.

Correspondence should be addressed to C. S. Colwell, Mental Retardation Research Center, University of California-Los Angeles, 760 Westwood Plaza, Los Angeles, CA 90024-1759.

Copyright $(\mathcal{1} 1995$ Society for Neuroscience $0270-6474 / 95 / 151704-10 \$ 05.00 / 0$
}

partate (NMDA), amino-3-hydroxy-5-methyl-4-isoazole propionic acid (AMPA), and kainate (KA) receptors. A variety of evidence indicates that each of these receptor subtypes are present within the neostriatum. For example, electrical stimulation of cortical inputs evokes excitatory postsynaptic potentials (EPSPs) in neostriatal neurons which are largely mediated by the AMPA/KA GluRs, although NMDA GluRs can also play a role (Herrling, 1985; Cherubini et al., 1988; Calabresi et al., 1990). Dysfunctions in these excitatory synapses have been suggested to play a role in the pathology of such diverse neurological disorders as Huntington's disease (DiFiglia, 1990) and obsessive-compulsive disorder (Baxter et al., 1992). Thus, understanding the mechanisms involved in the regulation and modulation of this synaptic connection may prove to be clinically important.

Recently, there have been reports that the adenylate cyclase cascade regulates glutaminergic synaptic transmission (e.g., Cerne et al., 1992; Chavez-Noriega and Stevens, 1992), and this regulation may be important in the neostriatum. First, both forskolin binding sites (Gchlert ct al., 1985; Worlcy ct al., 1986; Poat et al., 1988) and adenylate cyclase mRNA (Matsuoka et al., 1992; Glatt and Snyder, 1993) are abundant in this region. Second, ample evidence from biochemical studies indicates that forskolin- and receptor-mediated regulation of adenylate cyclase occurs in the neostriatum (e.g., Stoof and Kebabian, 1981; Daly et al., 1982; Battaglia et al., 1986; Matsuoka et al., 1992; Prezeau et al., 1992). Finally, dopanime and metabotropic GluRs have been shown to both regulate adenylate cyclase activity and modulate ionotropic GluR agonist-induced responses in this region (Cepeda et al., 1993; Colwell and Levine, 1994). Consequently, the purpose of the present study was to directly investigate whether cAMP-dependent regulation of both excitatory synaptic transmission and GluRs occurs in the neostriatum.

Experiments were designed to determine (1) the effects of forskolin on EPSPs recorded in neostriatal neurons, (2) whether these effects are mediated by $\mathrm{c} \Lambda \mathrm{MP}$-dependent protein kinase, (3) the role of tonic kinase and phosphatase activity in regulating the EPSP, (4) the effects of forskolin on membrane properties of neostriatal neurons, and (5) the effects of forskolin on NMDA and AMPA/KA GluR-induced responses in these neurons.

\section{Materials and Methods}

Preparation of neostriatal slices. Adult male Sprague-Dawley rats (Harlan Sprague-Dawley, Indianapolis, IN) were maintained in small groups with continuous access to food and water. After animals were killed by decapitation, brains were dissected and placed in cold oxygenated artificial cerebrospinal fluid (ACSF) containing (in $\mathrm{mM}$ ) $\mathrm{NaCl}$ 124, $\mathrm{NaHCO}_{3} 26, \mathrm{KCL} 5, \mathrm{MgSO}_{4} 2, \mathrm{NaH}_{2} \mathrm{PO}_{1} 1.25, \mathrm{CaCl}_{2} 2.4$, and glucose $10(\mathrm{pH} 7.2-7.4)$. Transverse sections $(400 \mu \mathrm{m})$ were cut and incubated in $\mathrm{ACSF}$ at $35-37^{\circ} \mathrm{C}$ for $1-2 \mathrm{hr}$. Tissue was then transferred 
to the recording chamber at least $30 \mathrm{~min}$ prior to recording. The slice rested upon filter paper in the "interface-type" recording chamber and was superfused continuously by oxygenated $\operatorname{ACSF}\left(35-37^{\circ} \mathrm{C}\right)$. A warm, humidified gas $\left(95 \% \mathrm{O}_{2}, 5 \% \mathrm{CO}_{2}\right)$ flowed over the top surface of the slice.

Intracellular recording. Intracellular recordings were obtained with glass microelectrodes filled with $3 \mathrm{~m}$ potassium acetate. DC resistances varied from $70-100 \mathrm{M} \Omega$ The signal was amplified by an active bridge circuit (Axoclamp 2A amplifier, Axon Instruments, Foster City, CA) and stored on videotape for later analysis. After a neuron was impaled, a baseline recording was obtained to ensure that the cell's membrane properties were stable. Baseline membrane potential was maintained throughout the course of the experiment by manually adjusting the DC current. This injected current was never more than $\pm 0.5 \mathrm{nA}$ and typically was not needed until $>90 \mathrm{~min}$ into the recording. Most data were collected without DC current injection. Hyperpolarizing current pulses (0.2-0.4 nA, $50 \mathrm{msec}$ duration, $0.5 \mathrm{per} \mathrm{sec})$ were applied throughout all experiments to measure conductance changes. In some neurons, the current-voltage relationship was obtained by injection of depolarizing and hyperpolarizing pulses (100 msec duration); the cell's input resistance was determined from the linear portion of the current-voltage plots. Membrane excitability was measured as the response of the neuron to depolarizing current pulses $(0.1 \mathrm{nA}$ steps, $500 \mathrm{msec}$ duration). Not all measurements were obtained for each cell. Most recordings were made from cells in the dorsomedial region of the neostriatum.

Electrophysiological information on the effects of experimental treatments on action potential (AP) and afterhyperpolarization (AHP) duration and amplitude was obtained by analyzing the first AP evoked by the current pulses. The AP amplitudes were measured from the start of the rising phase to the peak of depolarization, while durations were measured at half amplitude. The rise times were measured as the time from the start of the AP to the peak, while the fall tines were ineasured from the peak to the membrane's return to baseline potential. The amplitudes of the AHPs were measured from start of the AP to the maximal deflection of the hyperpolarization, while durations were determined as the time from the start of the hyperpolarization until the membrane potential returned to its baseline value.

In some cases, the recording electrodes were filled with a $2 \%$ solution of biocytin dissolved in $3 \mathrm{M}$ potassium acetate. After completion of the experiment, these slices were fixed in paraformaldehyde and then processed by standard techniques to identify recorded cells (Horikawa and Armstrong, 1988).

Electrical stimulation. The stimulating electrode used to evoke EPSPs consisted of a pair of $0.2 \mathrm{~mm}$ insulated stainless steel wires separated by a $0.5 \mathrm{~mm}$ shaft (David Kopf Instruments, Tujunga, CA). Contacts were exposed by $0.5 \mathrm{~mm}$. It was placed approximately $1-3 \mathrm{~mm}$ from the recording electrode. To activate the corticostriatal fibers, one tip was placed in the corpus callosum while the other was placed in the dorsal neostriatum. Stimuli consisted of $100 \mu \mathrm{sec}$ square wave pulses of varying amplitudes. Electrical stimulation evoked an EPSP which was blocked by GluR antagonists, low calcium solutions, or tetrodotoxin. The EPSP amplitudes were measured from the start of the rising phase to the peak depolarization, while durations were measured at half amplitude. Under control conditions, the EPSP amplitude was stable over the $1-2 \mathrm{hr}$ in which these experiments were typically performed.

Iontophoresis. For iontophoresis, a five-barrelled pipette was placed close $(100-200 \mu \mathrm{m})$ to the recording electrode. Iontophoretic and recording electrodes were held by separate electrode carriers. This configuration minimized electrical interactions between recording and microphoretic electrodes. Each barrel contained one of the following solutions: AMPA (20 mM, pH 8, Research Biochemical, Natick, MA), glutamate $(100 \mathrm{~mm}, \mathrm{pH} 8.5$, Sigma, St. Louis, MO), quisqualate (100 $\mathrm{mm}, \mathrm{pH} 8$, Tocris Neuramin, Bristol, UK), NMDA (100 mM, pH 8, Sigma), and saline for current balancing and controls. Not all drugs were used in each experiment. All drugs were iontophoretically ejected as anions and were prevented from diffusing out of the barrel by a positive holding current of 15-20 nA. In some experiments, current balancing was carried out through a barrel containing $1 \mathrm{~m} \mathrm{NaCl}$. No differences were observed between experiments with or without current balancing.

To study the effects of iontophoretically applied excitatory amino acid agonists, ejection currents were adjusted to induce reproducible submaximal responses. Ejection times ranged from $2-8 \mathrm{sec}$. The interval between ejection pulses varied from 2-3 min. Iontophoretic currents used to induce these responses ranged from 10 to $200 \mathrm{nA}$. Controls consisted of the application of negative currents of equal magnitude and duration through the saline-containing barrel of the pipette. In no case did the application of saline either cause membrane potential changes by itself $(>1 \mathrm{mV})$ or alter a cell's response to an EAA agonist. Perhaps due to the fact that the iontophoretic and recording electrodes are held by separate electrode manipulators, current artifacts as a result of iontophoretic stimulation are not commonly seen.

Drugs. Pharmacological agents applied in the bath included 2-amino3-phosphonopentanoic acid (AP-3), 2-amino-5-phosphonopentanoic acid (AP-5), bicuculline, 6-cyano-7-nitroquinozaline-2,3-dione (CNQX), forskolin and 1,9-dideoxyforskolin, okadaic acid and 1-nor-okadaone (Calbiochem, La Jolla, CA), Rp- and Sp-cAMPS, and tetrodotoxin (TTX, Sigma). Unless otherwise noted, drugs were purchased from Research Biochemicals. Forskolin and 1,9-dideoxyforskolin were mixed as a stock solution in dimethylsulfoxide (DMSO) and diluted to final concentration in ACSF. The final DMSO concentration was never higher that $0.25 \%$. In previous control experiments, this concentration of DMSO did not alter the synaptic-evoked response. Both forskolin and 1,9-dideoxyforskolin contained the same concentration of DMSO. Other bath-applied drugs were directly dissolved in ACSF. The protein kinase A inhibitor $\mathrm{IP}_{20}$-anide (PKI, $0.5 \mathrm{~mm}$ ) was dissolved in potassium acetate and applied intracellularly by allowing it to leak from the recording electrode.

Statistical analysis. Differences between average values for experimental and control groups were evaluated using paired $t$ tests. The ability of PKA antagonists to inhibit forskolin's actions was evaluated using a one-way ANOVA followed by Tukey's multiple comparison procedure. Values were considered significantly different if $p<0.05$. In the text, values are shown as means \pm SEM.

\section{Results}

A total of 86 neurons in the rat neostriatum were studied. Neostriatal neurons exhibited an average resting potential of -80.4 $\pm 1.1 \mathrm{mV}$ and an input resistance of $25.2 \pm 3.9 \mathrm{M} \Omega$ As many as $95 \%$ of the neurons in the neostriatum are projection neurons referred to as medium spiny neurons (Gerfen, 1992) and it is likely that most, if not all, of the data in the present study were collected from this cell type. In all cases examined (5/5), the neostriatal cells identified by intracellular injection of biocytin exhibited the morphological characteristics of medium spiny neurons.

\section{Forskolin reversibly enhances EPSPs recorded from neostriatal neurons}

Electrical stimulation of corticostriatal fibers evoked an EPSP in all cells tested $(n=61)$. The average peak depolarization was $13.1 \pm 0.6 \mathrm{mV}$ (range 4-37 mV). The average duration at half maximal amplitude was $11.1 \pm 0.8 \mathrm{msec}$ (range 9-16 msec). Bath application of forskolin (10 $\mu \mathrm{M}, 5-10 \mathrm{~min}$ ) enhanced the EPSP amplitude (156 $\pm 2 \%$ of pretreatment controls, $n=17$, $p<0.00001)$ and duration $(122 \pm 6 \%, p<0.01$, Fig. 1). In $10 / 17$ cases, the EPSP amplitude showed a short (5-10 min) depression prior to enhancement. However, this effect was not significant and was not further explored. The enhancement peaked $25 \pm 3 \mathrm{~min}(n=15)$ after the end of the forskolin treatment and was reversible in most cases (average recovery time $57 \pm 4 \mathrm{~min}$, range $40-80 \mathrm{~min}, n=13$, Fig. $2 C$ ). The magnitude of this potentiation increased after exposure to increasing concentrations of forskolin (Fig. 1B).

Forskolin has been reported to act directly on ion channels without action on the cAMP cascade (e.g., Laurenza et al., 1989). To test this possibility, the forskolin analog 1,9-dideoxyforskolin $(10 \mu \mathrm{M})$ was applied. This compound, which does not stimulate adenylate cyclase but mimics other actions of forskolin, did not have any consistent action on EPSP amplitude (Fig. $1 B ; 94 \pm 4 \%$ of controls, $n=4$ ).

One mechanism by which forskolin could enhance the EPSP 

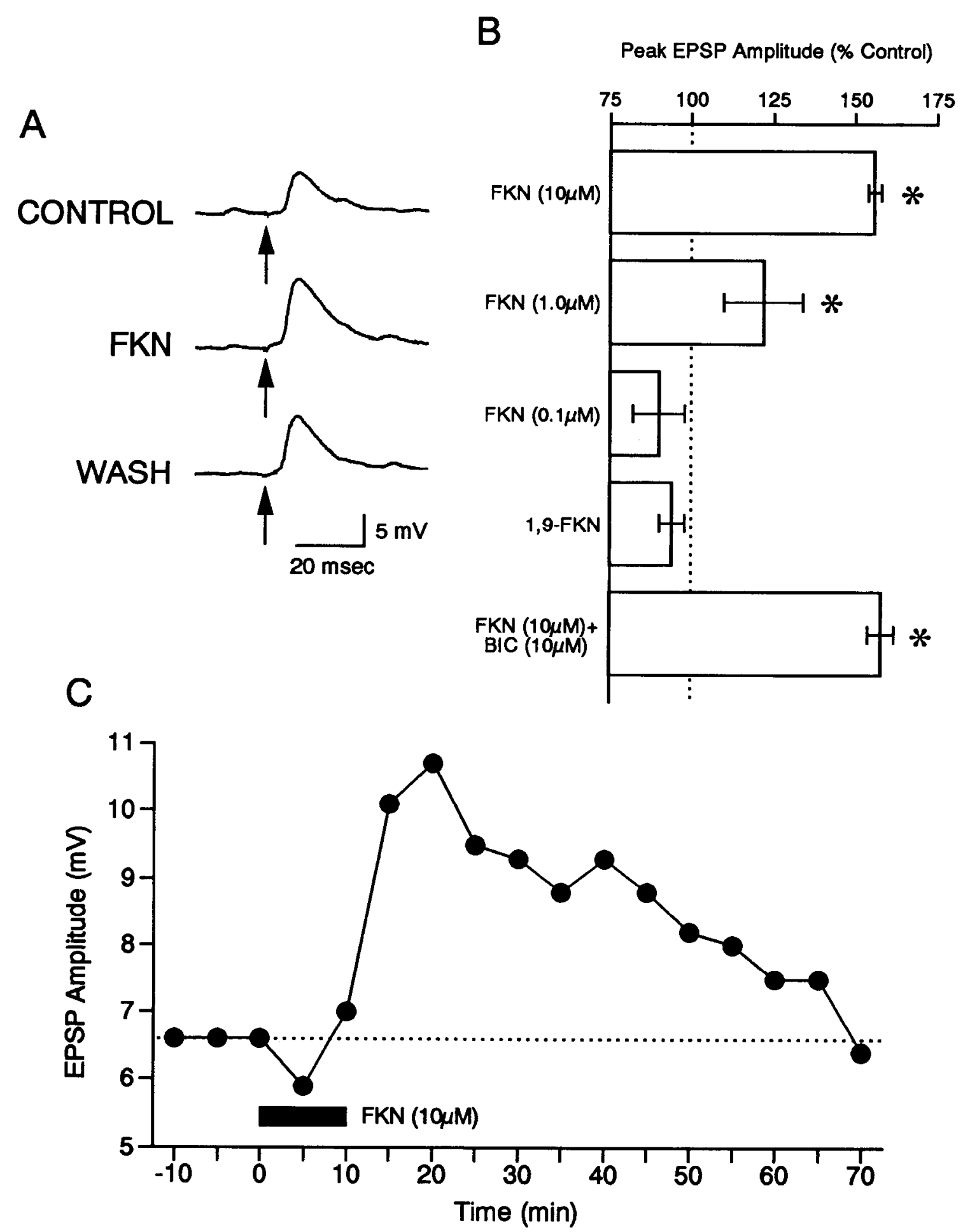

Figure 1. Forskolin enhances excitatory synaptic transmission in neostriatal neurons. A, Traces of intracellularly recorded EPSP evoked by electrical stimulation prior to, during, and after forskolin ( $F K N, 10 \mu \mathrm{M}$ in bath, $10 \mathrm{~min}$ ) treatment. Trace labeled "FKN" was recorded $10 \mathrm{~min}$ after end of forskolin treatment, while trace labeled "WASH" was recorded 40 min later. Arrow indicates time of electrical stimulation. Each trace is an average of four consecutive responses. $B$, Summary data showing enhancement of EPSP amplitude caused by forskolin $(F K N, 10.0 \mu \mathrm{M}, n=12 ;$ or 1.0 $\mu \mathrm{M}, n=8)$ or forskolin $(10.0 \mu \mathrm{M})$ in the presence of $\mathrm{GABA}_{\mathrm{A}}$ receptor antagonist bicuculline $(B I C, 10 \mu \mathrm{M}, n=4)$. Asterisks indicate those groups which were significantly different from pretreatment controls. Potentiation was not obscrved following treatment with lower concentrations of forskolin $(0.1 \mu \mathrm{M}, n=5)$ or with inactive analog 1,9 dideoxyforskolin $(10 \mu \mathrm{M}, n=4)$. Error bars indicate \pm SEM. $C$, EPSP amplitude as a function of time recorded prior to, during, and after bath application of forskolin ( $F K N$, indicated by flled rectangle). In this and subsequent figures, the dotted line indicates pretreatment values. Data shown in $A$ and $C$ was collected from a cell labeled with biocytin and subsequently identified as a medium spiny neuron. This cell had a resting membrane potential of $-85 \mathrm{mV}$. 
is through a decrease in $\mathrm{GABA}_{\mathrm{A}}$-mediated inhibition (e.g., Heuschneider and Schwartz, 1989; Porter et al., 1990). However, bath application of the $\mathrm{GABA}_{\mathrm{A}}$ receptor antagonist bicuculline does not alter the amplitude of EPSPs evoked by stimulation of corticostriatal fibers (Jiang and North, 1991). Furthermore, forskolin-induced enhancement of the EPSP was unaltered by the presence of bicuculline (Fig. $1 B$; peak EPSP amplitude $159 \pm 20 \%$ of controls, $n=4$ ). Thus, rcgulation of a $\mathrm{GABA}_{\mathrm{A}}$-mediated process is unlikely to be responsible for forskolin's enhancement of excitatory synaptic transmission.

\section{Forskolin-induced potentiation is attenuated by Rp-cAMPS and mimicked by $S p$-cAMPS}

If forskolin's enhancement of the evoked EPSP involves cAMPdependent protein kinase (PKA), then inhibiting this kinase's activity should prevent this enhancement while stimulating PKA should mimic the modulatory effects of forskolin. Application of the PKA inhibitor Rp-cAMPS (e.g., Van Haaster et al., 1984) decreased forskolin's actions (Fig. 2). When Rp-cAMPS (100 $\mu \mathrm{M}$ ) was applied $10 \mathrm{~min}$ before and continued $10 \mathrm{~min}$ after forskolin $(10 \mu \mathrm{M})$ treatment, the EPSP amplitude was not significantly altered (average peak $111 \pm 6 \%$ of pretreatment controls, $n=7$ ). Furthermore, bath application of the PKA activator Sp-cAMPS (Van Haaster et al., 1984; $100 \mu \mathrm{M}, 10 \mathrm{~min}$ ) produced an enhancement of EPSP amplitude in five out of six cases (Fig. $2 B$, peak amplitude $131 \pm 12 \%$ of controls, $n=6, p<0.05$ ).

\section{Inhibition of kinase and phosphatase activities can also alter} the evoked EPSP

Treatment with the PKA inhibitor Rp-cAMPS (100 $\mu \mathrm{M}, 5-10$ min) alone decreased the average EPSP amplitude $(92 \pm 3 \%$ of controls, $n=11, p<0.05$ ). In order to further explore this inhibitory action, the intracellularly active PKA inhibitor PKI (Cheng et al., 1986) was added to the recording electrode (0.5 $\mathrm{mM})$ and allowed to diffuse into the cell. While untreated controls typically maintain a stable EPSP amplitude (102 $\pm 4 \%, n$ $=11$ ), treatment with PKI produced a consistent decrease in the EPSP amplitude. After $30 \mathrm{~min}$, EPSP amplitude declined to 67 $\pm 7 \%$ of initial values $(n=7, p<0.005)$. At this point, the application of forskolin $(10 \mu \mathrm{M})$ reversed the inhibition caused by PKI and returned the EPSP amplitude to control levels (106 $\pm 11 \%$ of controls, $n=7$ ). Although this effect of forskolin was not significantly different from pretreatment controls, the increase was significant compared to the group treated with PKI alone $(p<0.05)$. These findings suggest that tonic PKA activity may regulate the synaptic-evoked response. In order to examine the possible role of phosphatase activity, the protein phosphatase inhibitor okadaic acid (Cohen et al., 1990) was applied. This treatment $(10 \mu \mathrm{M}, 10 \mathrm{~min})$ increased the EPSP amplitude (Fig. $2 B ; 147 \pm 13 \%, n=5, p<0.05)$. In contrast, lower doses of okadaic acid (0.5-1.0 $\mu \mathrm{M}, n=3$ ) or the analog 1-nor-okadaone $(n=2)$, which lacks phosphatase inhibitory activity, did not alter the evoked EPSP. At the $10 \mu \mathrm{M}$ concentration effective in the present study, okadaic acid acts as a nonselective inhibitor of protein phosphatases 1, 2A, and 2B (Bjalojan and Takai, 1988; Cohen et al., 1989).

Forskolin's effect on intrinsic membrane properties of neostriatal neurons does not explain the potentiation of the EPSP

In order to develop a better understanding of the ionic mechanisms responsible for the enhancement of the EPSP, the effects of forskolin on membrane properties of neostriatal neurons were examined. Bath application with forskolin did not significantly alter any of the parameters measured (Table 1). However, among individual neurons, reversible changes in membrane potential and input resistance were observed. Thus, possible effects of cAMP on the membrane properties of neostriatal cells do not adequately explain the consistent enhancement of the synapticevoked responses caused by forskolin.

\section{Forskolin enhanced the responsiveness of neostriatal neurons to GluR agonists}

One mechanism by which forskolin could potentiate synaptic transmission is by enhancing the postsynaptic response of neostriatal neurons to GluR activation. Under the conditions in which the present experiments were performed, the iontophoretic application of GluR agonists including glutamate, quisqualate, and AMPA induced depolarizing responses mediated by AMPA/KA GluRs; that is, these responses were blocked by the antagonist CNQX but not by AP-5 or AP-3. These agonists induced an average peak depolarization of $8.5 \pm 1 \mathrm{mV}$ (range $2-18 \mathrm{mV}, n$ $=13$ ) with an average duration (measured at half maximum amplitude) of $9.6 \pm 2.1 \mathrm{sec}$ (range $5-12 \mathrm{sec}$ ). Treatment with forskolin $(1-10 \mu \mathrm{M}, 10 \mathrm{~min})$ increased these responses to 161 $\pm 10 \%$ of pretreatment controls $(n=13, p<0.000001)$, while the duration also increased to $121 \pm 7 \%$ of controls $(p<0.01)$ (Fig. 3). TTX is a blocker of voltage-activated sodium channels and, consequently, of synaptic transmission. Forskolin's enhancement occurred with TTX $(1 \mu \mathrm{M}, n=8)$ in the bath and in the presence of the NMDA GluK antagonist AP-5 (10 $\mu \mathrm{M}, n$ $=4$ ). The enhancement of AMPA/KA GluR-induced responses peaked between $24 \pm 3 \mathrm{~min}$ after end of the forskolin treatment and on average recovered $46 \pm 4 \mathrm{~min}$ from the start of the wash (Fig. 3B). By these measures, the time course of forskolin's enhancement of AMPA/KA GluR-induced responses and EPSP amplitude were not significantly different.

Forskolin treatment also enhanced NMDA-induced responses (Fig. 4). Under the conditions in which the present experiments were performed, the iontophoretic application of NMDA acts through NMDA GluRs; that is, NMDA-induced responses were blocked by AP-5 but not by CNQX or AP-3. NMDA application produced an average peak depolarization of $8.0 \pm 1 \mathrm{mV}$ (range $3-14 \mathrm{mV}, n=12$ ), with a duration of $18.5 \pm 3.2 \mathrm{sec}$ (range $10-43 \mathrm{sec}$ ). Bath-applied forskolin (1-10 $\mathrm{M}, 10 \mathrm{~min}$ ) increased both the amplitude (peak depolarization $157 \pm 10 \%$ of pretreatment controls, $n=12, p<0.0001$ ) and duration (half amplitude duration $156 \pm 12 \%$ of controls, $p<0.01$ ) of the NMDAevoked responses. This enhancement occurred in the presence of TTX (1 $\mu \mathrm{M}, n=6)$ and the AMPA/KA GluR antagonist CNQX $(10 \mu \mathrm{M}, n=6)$. On average, the potentiation of the NMDA-induced response peaked $6 \pm 1 \mathrm{~min}$ after the end of forskolin treatment and reversed by $24 \pm 2$ min (Fig. $4 B$ ). By these measures, the time course of forskolin's enhancement of NMDA GluR-induced responses was significantly faster than forskolin's potentiation of EPSP amplitude $(p<0.01)$. In two neurons, it was possible to demonstrate that forskolin's enhancement of NMDA and AMPA/KA GluR-evoked responses occurred with different time courses in the same cell.

\section{Discussion}

The findings of this study demonstrate that cAMP/PKA-dependent mechanisms can actively regulate excitatory synaptic transmission in neostriatal brain slices. Activation of adenylate cy- 
A

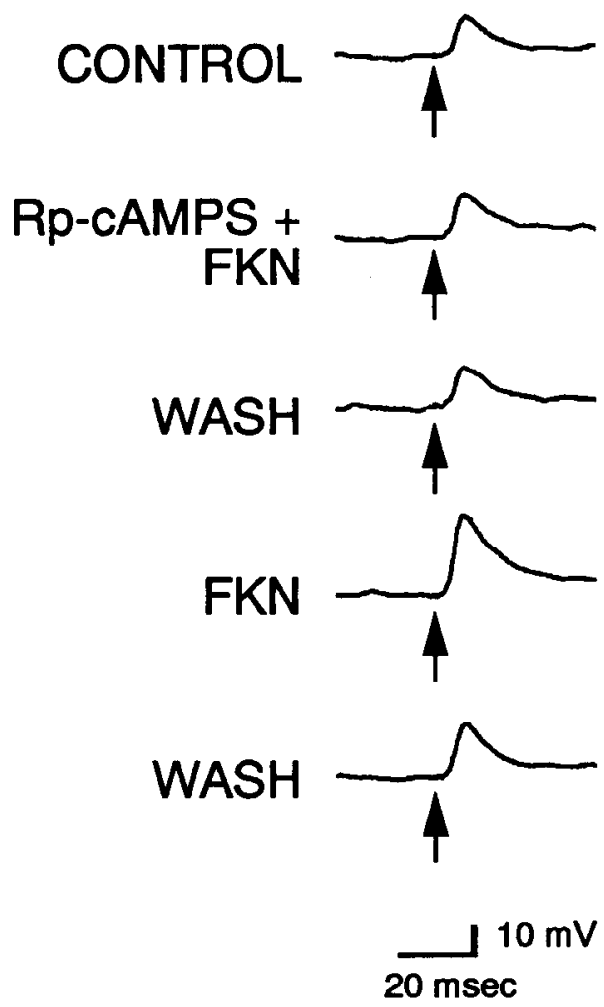

B

Peak EPSP Amplitude (\% Control)

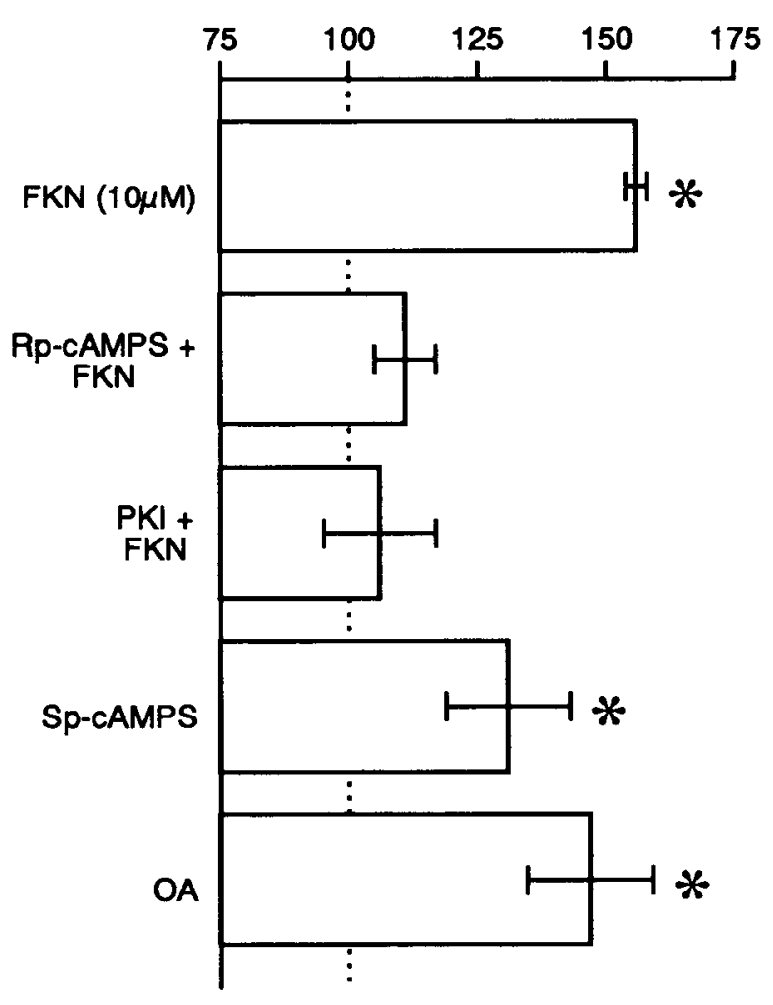

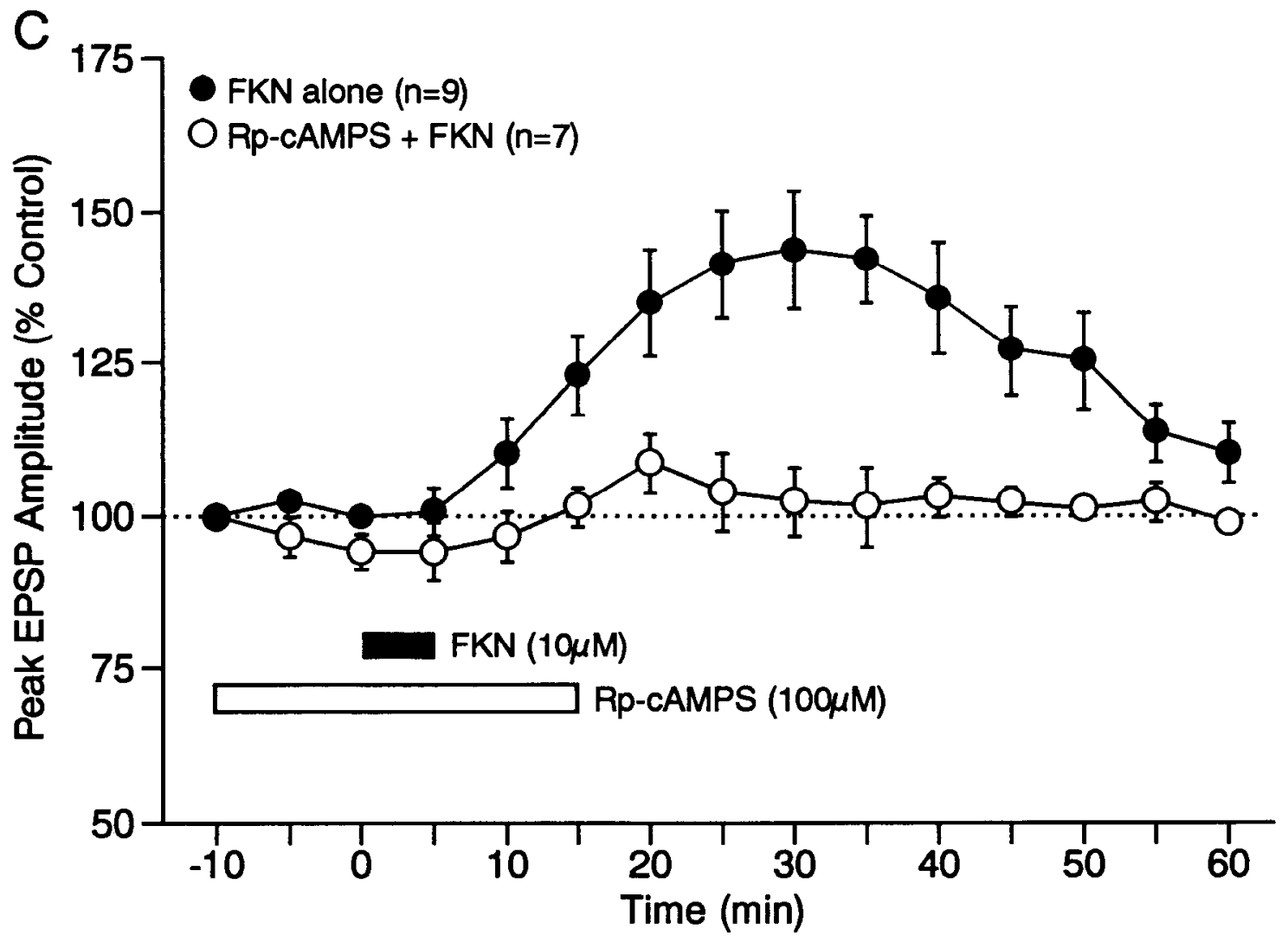

Figure 2. Rp-cAMPS attenuates forskolin-induced enhancement of synaptic transmission in neostriatal neurons. A, Example of data collected from one neuron. Top trace, Intracellularly recorded EPSPs evoked by electrical stimulation. Second trace, Rp-cAMPS (100 $\mu \mathrm{M})$ inhibited the forskolininduced potentiation $(F K N, 10 \mu \mathrm{M}, 10 \mathrm{~min})$. Third trace, Recovery, after $60 \mathrm{~min}$ wash in ACSF. Fourth trace, Forskolin was reapplied and potentiated the EPSP. Bottom trace, Recovery, after $60 \mathrm{~min}$ wash in ACSF. Arrow shows time of electrical stimulation. Each trace is the average of four 
Table 1. The effect of the bath application of forskolin $(10 \mu \mathrm{M}, 10 \mathrm{~min})$ on action potential

parameters was determined in eight neurons

Control Forskolin

Membrane potential $(\mathrm{mV})$

Input resistance $(\mathrm{M} \Omega)$

Threshold (mV)

Current to reach threshold (nA)

Action potential amplitude $(\mathrm{mV})$

$\Lambda$ ction potential duration (msec)

( $1 / 2$ maximal amplitude)

Action potential rise time (msec)

Action potential fall time $(\mathrm{msec})$

Afterhyperpolarization amplitude (mV)

Afterhyperpolarization duration (msec)

$\begin{array}{rr}81.0 \pm 2.5 & 80.4 \pm 2.4 \\ 22.0 \pm 3.1 & 24.7 \pm 3.4 \\ 31.8 \pm 2.6 & 33.4 \pm 3.3 \\ 1.0 \pm 0.1 & 1.0 \pm 0.1 \\ 67.0 \pm 4.1 & 68.5 \pm 5.0 \\ 0.87 \pm 0.02 & 0.90 \pm 0.05 \\ & \\ 0.85 \pm 0.05 & 0.90 \pm 0.05 \\ 2.0 \pm 0.1 & 2.0 \pm 0.1 \\ 7.0 \pm 0.6 & 7.3 \pm 0.5 \\ 54.8 \pm 11.8 & 52.9 \pm 9.1\end{array}$

In each of these cells, measurements were made at a time when forskolin had enhanced the EPSP amplitude. Values are shown as means $\pm \mathrm{SEM}, n=8$. Current pulses (500 msec duration) were used (o evoke action potentials. None of the values from forskolin-treated cells are significantly different from pretreatment controls.

clase by forskolin enhanced the amplitude and duration of the EPSP evoked by local stimulation in neostriatal slices. This effect was mimicked by the PKA activator Sp-cAMPS and inhibited by the PKA inhibitors Rp-cAMPS and PKI. Furthermore, application of these PKA inhibitors alone depressed while the phosphatase inhibitor okadaic acid enhanced this evoked synaptic response. Finally, forskolin was found to enhance the responses of neostriatal neurons evoked by the application of AMPA/KA and NMD $\Lambda$ GluR agonists.

It is likely that forskolin's potentiation of synaptic transmission in the neostriatum is mediated by activation of adenylate cyclase. It is well established that ${ }^{3} \mathrm{H}$-forskolin binding sites (Gehlert et al., 1985; Worley et al., 1986; Poat et al., 1988; Stockmeier and Zhang, 1993) as well as adenylate cyclase mRNA (Matsuoka et al., 1992; Glatt and Snyder, 1993) are abundant in the neostriatum. Furthermore, forskolin has been shown to both stimulate cAMP levels and activate PKA in neostriatal cells and tissue (Daly et al., 1982; Battaglia et al., 1986; Seaman and Daly, 1986; Chneiweiss et al., 1991; Matsuoka et al., 1992). In the present study, forskolin-induced potentiation occurred over a range of doses and with a time course consistent with a CAMP-dependent mechanism (Daly et al., 1982; Battaglia et al., 1986; Seaman and Daly, 1986; Matsuoka et al., 1992). Finally, treatment with the inactive analog 1,9-dideoxyforskolin (Laurenza et al., 1989) did not alter the evoked EPSP.

If forskolin enhances synaptic transmission through PKA, then this enhancement should be blocked by inhibiting PKA activity and mimicked by stimulating PKA. Application of the competitive PKA inhibitor Rp-cAMPS attenuated both the amplitude and duration of forskolin's potentiation. Since Rp-cAMPS can inhibit cyclic GMP-dependent kinase (PKG) as well as PKA (Hofmann et al., 1985), the effect of the intracellularly active PKA inhibitor PKI was also determined. PKI is a specific inhibitor of the catalytic subunit of PKA and has little or no effect on other kinases including PKG (Cheng et al., 1986). PKI alone inhibited EPSP amplitude and when forskolin was applied the EPSP amplitude was either unaffected or returned to original control levels. Evidence for the role of PKA was further strengthened by the finding that application of the PKA activator $\mathrm{Sp}$-cAMPS mimicked the effects of forskolin in enhancing the EPSP amplitude. Thus, the results with the PKA agonist (SpcAMPS) and the PKA antagonists (Rp-cAMPS, PKI) demonstrate that PKA-dependent mechanisms regulate synaptic transmission in the neostriatum.

The observation that application of PKA inhibitors Rp-cAMPS and PKI reduced the EPSP amplitude indicates that PKA is tonically active in regulating synaptic transmission in neostriatal neurons. In addition, a role for tonic phosphatase activity is suggested by the finding that the protein phosphatase inhibitor okadaic acid enhanced the EPSP amplitude. Together, these results suggest that the balance between tonic kinase and phosphatase activity regulates the amplitude of evoked synaptic responses in the neostriatum. Interestingly, in cultured hippocampal neurons, inhibiting PKA activity reduces the AMPA/KA GluR-mediated responses while inhibiting phosphatase activity has the opposite effect (Greengard et al., 1991; Wang et al., 1991). Since the neostriatal EPSP is primarily mediated by AMPA/KA GluRs, a PKA-dependent modulation of these receptors may explain the potentiation of synaptic-evoked responses.

In the present study, forskolin potentiated responses evoked by the iontophoretic application of AMPA/KA GluR agonists. This effect is likely to be mediated postsynaptically since responses were evoked under conditions in which synaptic transmission was blocked (bath-applied TTX). The magnitude and time course of forskolin's enhancement of AMPA/KA GluRevoked responses was similar to that of forskolin's potentiation of evoked EPSP (see Fig. 3). A variety of evidence indicates

$\leftarrow$

consecutive responses. Resting membrane potential was $-83 \mathrm{mV} . B$, Summarized results showing that EPSP amplitude was enhanced by forskolin $(F K N$, same data shown in Fig. $1 B)$, Sp-cAMPS (100 $\mu \mathrm{M}, 10 \mathrm{~min}, n=5)$, and okadaic acid $(O A, 10 \mu \mathrm{M}, 10 \mathrm{~min}, n=5)$. Asterisks indicate those groups which were significantly different from pretreatment controls. The forskolin-induced potentiation was attenuated by bath application of RpcAMPS $(100 \mu \mathrm{M}, 20-25 \mathrm{~min})$ or intracellular application of PKI $(0.5 \mathrm{~mm})$. Neither of these groups were significantly different from pretreatment controls. Error bars indicate \pm SEM. $C$, Time course of Rp-cAMPS's actions. average EPSP amplitude in slices treated with forskolin $(F K N$, $10 \mu \mathrm{M}$, filled rectangle) alone. $O$, average EPSP amplitude in slices treated with Rp-cAMPS (100 $\mu \mathrm{M}$, open rectangle) as well as forskolin. In presence of Rp-cAMPS, forskolin does not significantly alter the evoked EPSP amplitude. Error bars indicate \pm SEM. 
A

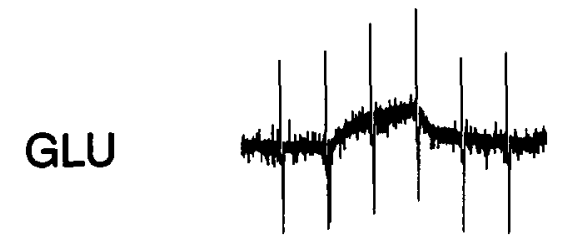

CONTROL

FKN
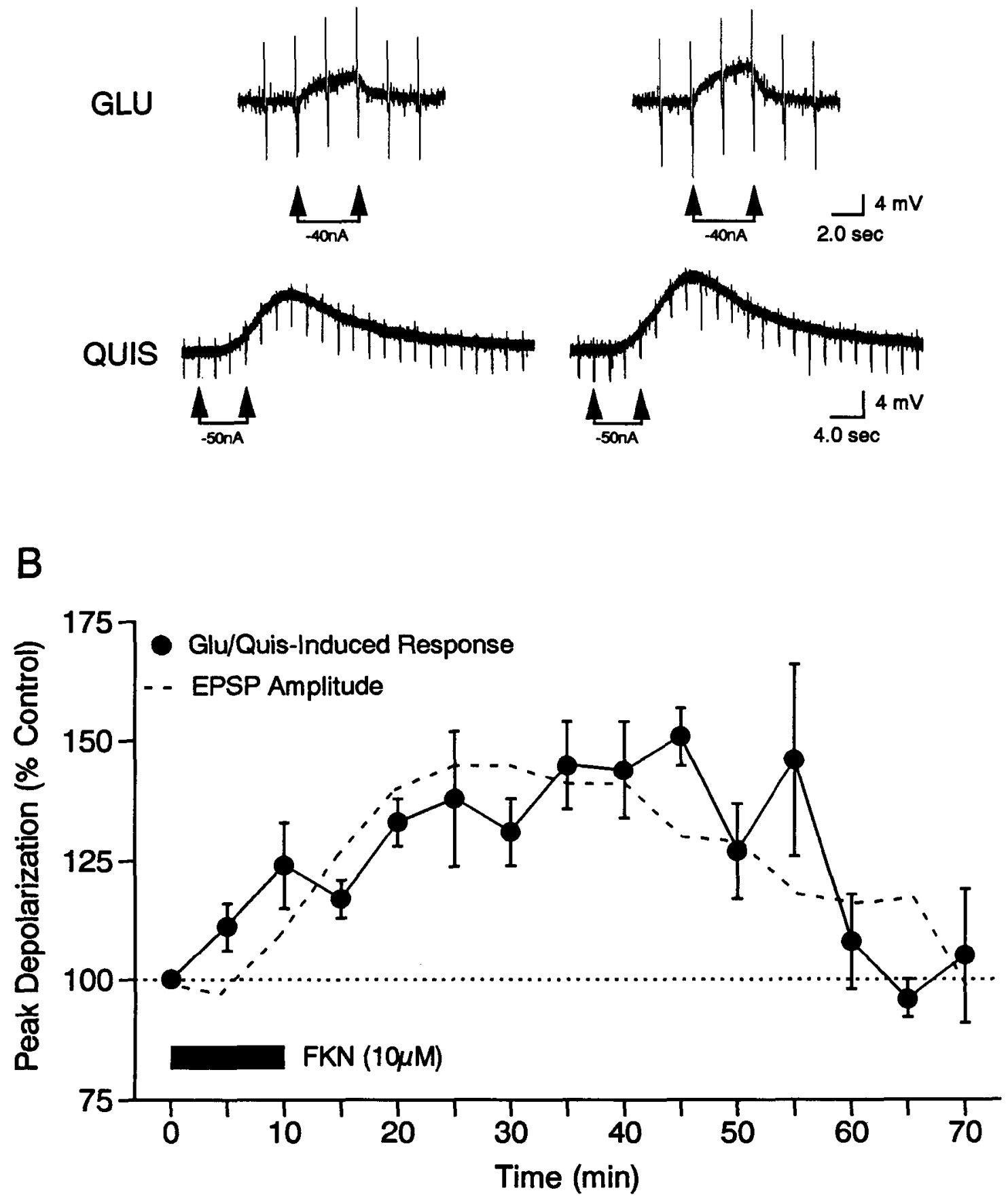

Figure 3. Forskolin enhances AMPA/KA GluR-induced responses. A, Intracellularly recorded responses to iontophoretically applied glutamate (GLU, top traces) and quisqualate (QUIS, bottom traces) from two cells prior to and after forskolin treatment (10 $\mu \mathrm{M}, 10 \mathrm{~min})$. Data collected in the presence of TTX $(1 \mu \mathrm{M})$ and the NMDA GluR antagonist AP-5 $(10 \mu \mathrm{M})$. In this and in Figure $4 A$, the arrows indicate the onset and offset of iontophoretic treatments, and hyperpolarizing current pulses $(0.4 \mathrm{nA}, 50 \mathrm{msec}$ duration, $0.5 \mathrm{~Hz})$ were applied as a measure of membrane conductance. $B$, Time course of forskolin's ( $F K N$, filled rectangle) enhancement of AMPA/KA GluR-mediated responses $(0, n=13)$. Long dashed line illustrates effects of forskolin on EPSP amplitude.

that these receptors can be modulated by cAMP-dependent processes (see discussion below). In the neostriatum, a previous study reported that the D2 receptor agonist quinpirole inhibited responses evoked by AMPA/KA GluR agonists (Cepeda et al., 1993). Since D2 receptor activation inhibits adenylate cyclase and thus decreases PKA activity, it is possible that DA's regu- lation of non-NMDA GluR-evoked responses is mediated via a decrease in PKA activity. Certainly, the present results are consistent with the hypothesis that CAMP/PKA-dependent mechanisms potentiate evoked EPSPs by altering the neostriatal cell's response to glutamate.

Forskolin also enhanced NMDA GluR-evoked responses. 
A

NMDA

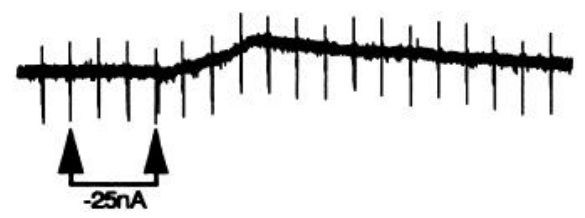

CONTROL

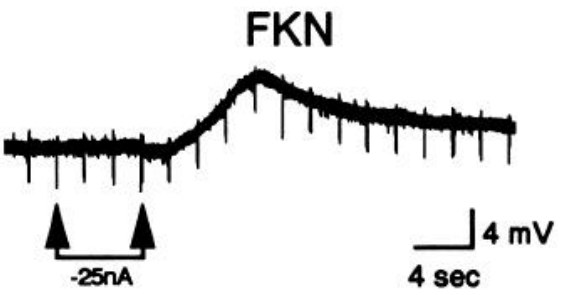

NMDA
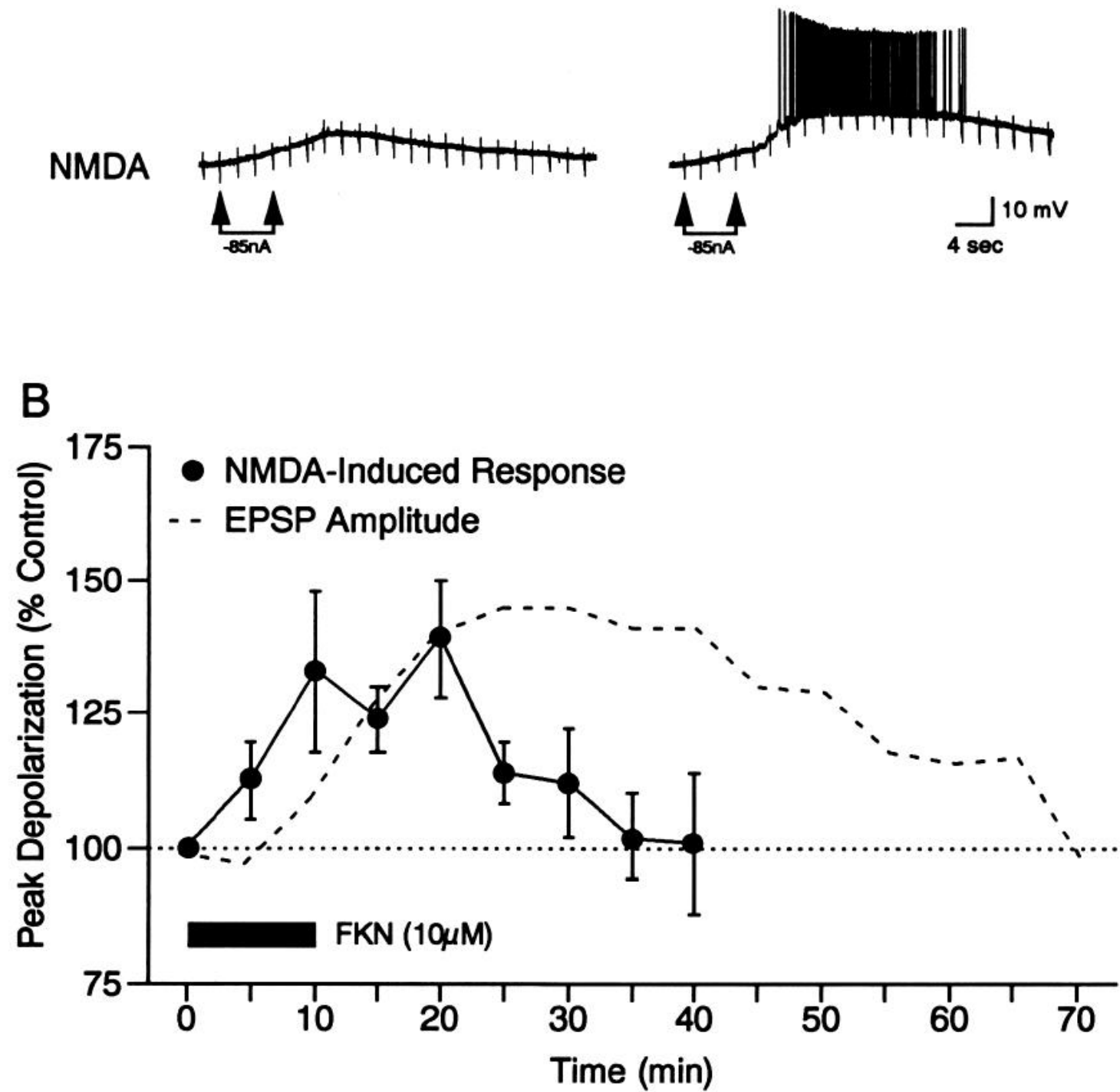

Figure 4. Forskolin enhances NMDA-induced responses. A, Intracellularly recorded responses to iontophoretically applied NMDA from two cells prior to and after forskolin $(10 \mu \mathrm{M}, 10 \mathrm{~min})$ treatment. In top traces, experiments were run in the presence of TTX (1 $\mu \mathrm{M})$ and the AMPA/KA GluR antagonist CNQX $(10 \mu \mathrm{M})$, while bottom traces were collected from a cell in normal ACSF. B, Time course of forskolin's (FKN, filled box) potentiation of NMDA GluR-induced responses (O). Long dashed line shows effects of forskolin on EPSP amplitude.

This enhancement is likely due to postsynaptic NMDA GluR activation since it occurred in the presence of TTX and CNQX. The time course of this potentiation was quite distinct from that of forskolin's regulation of either AMPA/KA GluR-evoked responses or evoked EPSPs (Fig. 4). Evidence for cAMP/PKAdependent potentiation of NMDA-evoked response has also been found in cultured spinal cord neurons (Cerne et al., 1993) but not in other preparations (Greengard et al., 1991; Wang et al., 1991; Durand et al., 1992). In the neostriatum, a recent study found that dopamine, acting through D1 receptors, potentiates NMDA-evoked responses (Cepeda et al., 1993). The finding that forskolin produces a similar effect suggests that dopamine acts through a cAMP-dependent mechanism to regulate the NMDA receptor in neostriatal tissue.

Although cAMP and PKA could act either pre- or postsynaptically to enhance synaptic transmission, evidence indicates that postsynaptic mechanisms are involved. First, forskolin alters the responsiveness of neostriatal neurons to GluR agonists under 
conditions in which synaptic transmission is blocked (bath-applied TTX). In addition, the striking parallels in the magnitude and time course of forskolin's potentiation of evoked EPSPs and of AMPA/KA GluR-evoked responses (Fig. 3) suggest that the same mechanism underlies both phenomena. Finally, the fact that the intracellularly applied kinase inhibitor PKI attenuates forskolin's enhancement of the evoked EPSP further supports a postsynaptic site of action. These results, however, do not exclude the possibility that presynaptic mechanisms are also involved; previous studics have found cvidence for cAMP regulation of presynaptic transmitter release (e.g., Castellucci et al., 1980; Heuschneider and Schwart7, 1989; Chavez-Noriega and Stevens, 1994).

The postsynaptic regulation by PKA of neuronal responses to GluR agonists can be explained by at least two mechanisms. First, PKA may directly phosphorylate GluRs and thus regulate GluR agonist-evoked responses. For example, cAMP/PKA-dependent potentiation of AMPA/KA GluR-mediated responses has been described in a variety of preparations (Knapp and Dowling, 1987; Linman et al., 1989; Knapp et al., 1990; Greengard et al., 1991; Mori-Okamota et al., 1991; Wang et al., 1991; Keller et al., 1992; Raymond et al., 1993b; Wang et al., 1993). At least in expression systems, GluR6 is directly phosphorylated and preventing this phosphorylation eliminates PKA-mediated potentiation (Raymond et al., 1993; Wang et al., 1993). However, not all GluR subunits appear to be directly phosphorylated by PKA (McGlade-McCulloh et al., 1993; Tan et al., 1994) and forskolin's potentiation of GluR-mediated responses in the neostriatum could be due to another mechanism. One alternative is that PKA may phosphorylate a regulatory protein which in turn indirectly alters GluR-induced responses. For example, inhibitors of protein phosphatase activity (DARPP-32 and phosphatase inhibitor 1) have been found in neostriatal neurons (Nairn et al., 1988). These regulatory proteins, when phosphorylated by PKA, will inhibit phosphatase 1 (Walaas et al., 1983; Hemmings et al., 1984; Williams et al., 1986). The observation that application of the phosphatase inhibitor okadaic acid mimics the effects of cAMP/PKA activation on the evoked EPSP is at least consistent with this possibility. Thus, PKA may modulate GluR-evoked responses either by directly phosphorylating the receptors or indirectly through regulation of phosphatase activity.

A growing body of evidence suggests that regulation of synaptic communication through phosphorylation/dephosphorylation could be common (e.g., Nairn et al., 1985; Raymond et al., 1993a). In the present study, the possibility that this regulation occurs in the neostriatum was examined by determining the effects of pharmacological manipulation of PKA and phosphatase activity on excitatory synaptic transmission. Among other results, treatments which increase protein phosphorylation (i.e., increase in kinase activity or decrease in phosphatase activity) enhanced synaptic-evoked responses, while treatments which decrease protein phosphorylation decreased these responses. At least some of this modulation can be explained by a postsynaptic regulation of the neostriatal neuron's response to GluR agonists. Limited evidence for cAMP-dependent modulation of excitatory synaptic transmission has been previously described (e.g., Cerne et al., 1992; Chavez-Noriega and Stevens, 1992). These results suggest that the balance between kinase and phosphatase activity may play a general role in regulating synaptic transmission in the central nervous system.

\section{References}

Battaglia G, Norman AB, Hess EJ, Creese I (1986) Forskolin potentiates the stimulation of rat striatal adenylate cyclase mediated hy D-1 dopamine receptors, guanine nucleotides, and sodium fluoride. J Neurochem 46:1180-1185.

Baxter L, Schwarz J, Bergman K, Szuba M, Guze B, Mazziotta J, Alazraki A, Selin C, Ferng H, Munford P, Phelps M (1992) Arch Gen Psychiatry 49:681-689.

Bialojan C, Takai A (1988) Inhibitory effect of a marine-sponge toxin, okadaic acid, on protein phosphatases. Biochem J 256:283-290.

Calabresi P, Mercuri N, Stanzione P, Stefani A, Bernardi G (1987) Intracellular studies on the dopamine-induced firing inhibition of neostriatal neurons in vitro: evidence for D1 receptor involvement. Neuroscience 20:757-771.

Calabresi P, Mercuri NB, Bernardi G (1990) Synaptic and intrinsic control of membrane excitability of neostriatal neurons. II. An in vitro analysis. J Neurophysiol 63:663-675.

Castellucci VF, Kandel ER, Schwartz JH, Wilson FD, Nairn AC, Greengard $P$ (1980) Intracellular injection of the catalytic subunit of cyclic AMP-dependent protein kinase simulates facilitation of transmitter release underlying behavioral sensitization in Aplysia. Proc Natl Acad Sci USA 77:7492-7496.

Cepeda C, Buchwald NA, Levine MS (1993) Neuromodulatory actions of dopamine in the neostriatum are dependent upon the excitatory amino acid receptor subtypes activated. Proc Natl Acad Sci USA 90: 9576-9580.

Cerne R, Jiang M, Randic M (1992) Cyclic adenosine 3'5'-monophosphate potentiates excitatory amino acid and synaptic responses of rat spinal dorsal horn neurons. Brain Res 596:111-123.

Cerne R, Rusin KI, Randic M (1993) Enhancement of the $N$-methyl$\mathrm{D}$-aspartate response in spinal dorsal horn neurons by cAMP-dependent protein kinase. Neurosci Lett 161:124-128.

Chavez-Noriega LE, Stevens CF (1992) Modulation of synaptic efficacy in field CAl of the rat hippocampus by forskolin. Brain Res $574: 85-92$.

Chavez-Noriega LE, Stevens CF (1994) Increased transmitter release at excitatory synapses produced by direct activation of adenylate cyclase in rat hippocampal slices. J Neurosci 14:310-317.

Cheng HC, Kemp BF, Pearson RB, Smith AJ, Misconi I, Van Patten SM, Walsh DA (1986) A potent synthetic peptide inhibitor of the cAMP-dependent protein kinase. J Biol Chem 261:989-992.

Cherubini E, Herrling PL, Lanfumey L, Stanzione P (1988) Excitatory amino acids in synaptic excitation of rat striatal neurones in vitro. J Physiol (Lond) 400:677-690.

Chneiweiss H, Cordier J, Glowinski J (1991) Cyclic AMP accumulation induces a rapid desensitization of the cyclic AMP-dependent protein kinase in mouse striatal neurons. J Neurochem 57:1708-1715.

Cohen P, Holmes CFB, Tsukitani Y (1990) Okadaic acid: a new probe for the study of cellular regulation. Trends Biochem Sci 15:98-102.

Colwell CS, Levine MS (1994) Metabotropic glutamate receptors modulate NMDA receptor function in neostriatal neurons. Neuroscience 61:497-507.

Daly JW, Padgett W, Seamon KB (1982) Activation of cyclic AMPgenerating systems in brain membranes and slices by the diterpene forskolin: augmentation of receptor-mediated responses. J Neurochem 38:532-544.

DiFiglia M (1990) Excitotoxic injury of the neostriatum: a model for Huntington's disease. Trends Neurosci 13:286-289.

Durand GM, Gregor P, Zheng X, Bennett MVL, Uhl GR, Zukin RS (1992) Cloning of an apparent splice variant of the rat NMDA receptor with altered sensitivity to polyamines and activators of protein kinase C. Proc Natl Acad Sci USA 89:9359-9363.

Fonnum F, Storm-Mathisen J, Divac I (1981) Biochemical evidence for glutamate as a neurotransmitter in cortico-striatal and cortico-thalamic fibers in the rat brain. Neuroscience 6:863-873.

Gehlet DR, Dawson TM, Yamamura HI, Warmsley J.K (1985) Quantitative autoradiography of $\left[{ }^{3} \mathrm{H}\right]$ forskolin binding sites in the rat brain. Brain Res 361:351-360.

Gerfen CR (1992) The neostriatal mosaic: multiple levels of compartmental organization in the basal ganglia. Annu Rev Neurosci 15:285320.

Glatt CE, Snyder SH (1993) Cloning and expression of an adenylyl cyclase localized to the corpus striatum. Nature 361:536-538.

Greengard P, Jen J, Nairn AC, Stevens CF (1991) Enhancement of the 
glutamate response by cAMP-dependent protein kinase in hippocampal neurons. Science 253:1135-1138.

Hemmings HC, Greengard P, Tung HYL, Cohen P (1984) DARPP-32, a dopamine regulated neuronal phosphoprotein, is a potent inhibitor of protein phosphatase-1. Nature 310:503-505.

Herrling PL (1985) Pharmacology of the corticocaudate excitatory postsynaptic potential in the cat: evidence for its mediation by quisqualate- or kainate-receptors. Neuroscience 14:417-426.

Heushneider G, Schwartz RD (1989) cAMP and forskolin decrease $\gamma$-aminobutyric acid-gated chloride flux in rat brain synaptoneurosomes. Proc Natl Acad Sci USA 86:2938-2942.

Hofmann F, Gensheimer HP, Landgraf W, Hullin R, Jastroff B (1985) Diastereomers of adenosine $3^{\prime}, 5^{\prime}$-monothiophosphate antagonize the action of cGMP-dependent protein kinase. Eur J Biochem 150:185188.

Hollmann M, Heinemann S (1994) Cloned glutamate receptors. Annu Rev Neurosci 17:31-108.

Horikawa K, Armstrong WE (1988) A versatile means of intracellularly labeling: injection of biocytin and its detection with avidin conjugates. J Neurosci Methods 25:1-11.

Jiang ZG, North RA (1991) Membrane properties and synaptic responses of rat striatal neurones in vitro. J Physiol (Lond) 443:533553.

Keller BU, Hollmann M, Heinemann S, Konnerth A (1992) Calcium influx through subunits GluR1/GluR3 of kainate/AMPA receptor channels is regulated by cAMP dependent protein kinase. EMBO J 11:891-896.

Knapp AG, Dowling JE (1987) Dopamine enhances excitatory amino acid-gated conductances in cultured retinal horizonal cells. Nature $325: 437-439$.

Knapp AG, Schmidt KF, Dowling JE (1990) Dopamine modulates the kinetics of ion channels gated by excitatory amino acids in retinal horizontal cells. Proc Natl Acad Sci USA 87:767-771.

Laurenza A, Sutkowski EM, Seamon KB (1989) Forskolin: a specific stimulator of adenylyl cyclase or a diterpene with multiple sites of action? Trends Pharmacol Sci 10:442-447.

Liman ER, Knapp AG, Dowling JE (1989) Enhancement of kainategated currents in retinal horizontal cells by cyclic AMP-dependent protein kinase. Brain Res 481:399-402.

Matsuoka I, Giuli G, Poyard M, Stengel D, Parma J, Guellaen G, Hanaune J (1992) Localization of adenylyl and guanylyl cyclase in rat brain by in situ hybridization: comparison with calmodulin mRNA distribution. J Neurosci 12:3350-3360.

McGeer PL, McGeer EG, Shorer V, Singh K (1977) A glutamatergic corticostriatal path? Brain Res 128:369-373.

McGlade-McCulloh E, Yamamoto H, Tan S-E, Brickey DA, Soderling TR (1993) Phosphorylation and regulation of glutamate receptor by calcium/calmodulin-dependent protein kinase II. Nature 362:640642.

Monaghan DT, Bridges RJ, Cotman CW (1989) The excitatory amino acid receptors: their classes, pharmacology, and distinct properties in the function of the central nervous system. Annu Rev Pharmacol Toxicol 29:365-402.

Mori-Okamoto J, Namii Y, Tatsuno J (1991) Subtypes of adrenergic receptors and intracellular mechanisms involved in modulatory effects of noradrenaline on glutamate. Brain Res 539:67-75.

Nairn AC, Hemmings HC, Greengard P (1985) Protein kinases in the brain. Annu Rev Biochem 54:931-976.

Nairn AC, Hemmings HC, Walaas SI, Greengard P (1988) DARPP-32 and phosphatase inhibitor-1, two structurally related inhibitors of protein phosphatase-1, are both present in striatonigral neurons. J Neurochem 50:257-262.

Poat JA, Cripps HE, Iverson LL (1988) Differences between highaffinity forskolin binding sites in dopamine-rich and other regions of rat brain. Proc Natl Acad Sci USA 85:3216-3220.

Porter NM, Twyman RE, Uhler MD, MacDonald RL (1990) Cyclic $A M P$-dependent protein kinase decrease $\mathrm{GABA}_{\mathrm{A}}$ receptor current in mouse spinal neurons. Neuron 5:789-796.

Prezeau L, Manzoni O, Homburger V, Sladeczek F, Curry K, Bockaert J (1992) Characterization of a metabotropic glutamate receptor: direct negative coupling to adenylate cyclase and involvement of a pertussis toxin-sensitive $G$ protein. Proc Natl Acad Sci USA 89: $8040-8044$.

Raymond LA, Blackstone CD, Huganir RL (1993a) Phosphorylation of amino acid neurotransmitter receptors in synaptic plasticity. Trends Neurosci 16:147-153.

Raymond LA, Blackstone CD, Huganir RL (1993b) Phosphorylation and modulation of recombinant GluR6 glutamate receptors by $\mathrm{c} \Lambda \mathrm{MP}$ dependent protein kinase. Nature 361:637-641.

Seaman KB, Daly JW (1986) Forskolin: its biological and chemical properties. Adv Cyclic Nucleotide Res 20:1-150.

Stockmeier CA, Zhang Y (1993) Characterization of $\left[{ }^{3} \mathrm{H}\right]$ forskolin binding sites in the human caudate nucleus. Brain Res 610:156-161.

Stoof JC, Kebabian JW (1981) Opposing roles for D-1 and D-2 dopamine receptors in efflux of cyclic AMP from rat neostriatum. Nature 294:366-368.

Tan S-E, Wenthold RJ, Soderling TR (1994) Phosphorylation of AMPA-type glutamate receptors by calcium/calmodulin-dependent protein kinase II and protein kinase $\mathrm{C}$ in cultured hippocampal neurons. J Neurosci 14:1123-1129.

Van Haaster PJM, Driel RV, Jastorff B, Baraniak J, Stec WJ, DeWit RJW (1984) Competitive cAMP antagonists for cAMP-receptor proteins. J Biol Chem 259:10020-10024.

Walass SI, Aswad DW, Greengard P (1983) A dopamine- and cyclic AMP-regulated phosphoprotein enriched in dopamine-innervated brain regions. Nature 301:69-71.

Wang L-Y, Salter MW, MacDonald JF (1991) Regulation of kainate receptors by cAMP-dependent protein kinase and phosphatases. Science 253:1132-1135.

Wang L-Y, Traverna FA, Huang W-P, MacDonald JF, Hampson DR (1993) Phosphorylation and modulation of a kainate receptor (GluR6) by cAMP-dependent protein kinase. Science 259:11731175 .

Williams KR, Hemmings HC, LoPresti MB, Kornigsberg WH, Greengard P (1986) DARPP-32, a dopamine- and cyclic AMP-regulated neuronal phosphoprotein. Primary structure and homology with protein phosphatase inhibitor-1. J Biol Chem 261:1890-1903.

Worley PF, Baraban JM, DeSouza EB, Snyder SH (1986) Mapping second messenger systems in the brain: differential localizations of adenylate cyclase and protein kinase C. Proc Natl Acad Sci USA 83: 4053-4057. 